\title{
Losses Modeling of the Electric Vehicles Power Chain
}

\author{
Moez Hadj Kacem ${ }^{1}$, Souhir Tounsi ${ }^{2}$, Rafik Neji ${ }^{1}$ \\ ${ }^{1}$ National School of Engineers of Sfax, Sfax University, LETI-Laboratory, Sfax, Tunisia \\ ${ }^{2}$ National School of Electronics and Telecommunications of Sfax, Sfax University, SETIT Research Unit, Sfax, Tunisia
}

Email address:

souhir.tounsi@enetcom.rnu.tn (S. Tounsi)

\section{To cite this article:}

Moez Hadj Kacem, Souhir Tounsi, Rafik Neji. Losses Modeling of the Electric Vehicles Power Chain. International Journal of Electrical Components and Energy Conversion. Vol. 1, No. 2, 2015, pp. 49-54. doi: 10.11648/j.ijecec.20150102.11

\begin{abstract}
In this paper, we present a comparative study of two Electric Vehicle power chain, one in IGBTs and the other with electromagnetic switches (IEs) in order to select the most efficient in point of view of energy economy and production costs. In this context, a model of the total losses of the two power chains is developed an implanted under Matlab-Simulink environnement.
\end{abstract}

Keywords: Electromagnetic Switches, Electric Vehicle, Converter, IGBT, Losses Model

\section{Introduction}

The major issue of land transport in future years is the economy of energy. The electric vehicle (EV) is part of autonomy as a reliable candidate to solve the problem of energy shortage. The direct drives reinforce this logic power saving by canceling losses in electrical devices and increasing their energy efficiency [1-10].

The static converter is one of the fundamental elements of $\mathrm{EV}$. It is the interface between the battery and the electric motor, its role is to convert the output power of the battery with the consumed by the main engine and to adapted deliver the electrical power to the set of user. So the static converter, driven by the controller, will help to accelerate or decelerate the motor (and the car).

In fact, we present in this paper a comparative study of two Electric Vehicle power chains, one in IGBTs and the other IEs in order to select the most efficient [1-9].

\section{Power Chain Structure}

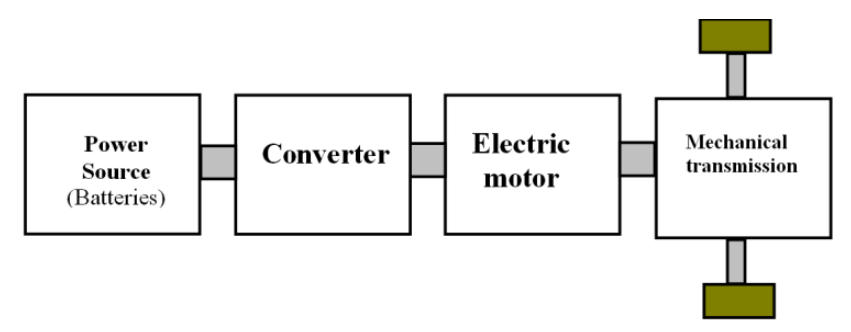

Figure 1. Structure of the chain drive.
A power train of an electrical vehicle is conventionally composed of an electric motor, an electronic system (power source and control) and a mechanical linkage system (gear, differential and wheels), Fig. 1.

The selected power converter is a two-level inverter voltage. This structure is the least expensive compared to others and offers good quality forms of motor power wave voltages and currents, which leads to a good dynamic characteristic of EVs. Two inverter types are studied; the firstwith IGBT and the other electromagnetic switches (IEs). The latter structure has the disadvantage of low switching frequency (Below $150 \mathrm{~Hz}$ ) [5], But it is the cheapest and haven't the problem of the floating potential, since each inverter arm is controlled by a single electromagnet. As against the IGBT structure offers the possibility to achieve a switching frequency of $8000 \mathrm{~Hz}$ [6] which leads to a good quality of the dynamic characteristic of $\mathrm{EVs}$, it raises a lot of disadvantages which can be made, as examples [9-12]:

- The Energy losses leading to a reduced range for a fixed energy stored as heat in the transistors and diodes, leading to the incorporation of a cooling system in most cases.

- The floating potential,

- Thestatic and dynamic Luch-upusually leading to the deterioration of the converter.

\section{Losses Modelling}

This model relates both chain structures of power to the IGBT and the other electromagnetic switch (IE), in order to select the one with the lowest losses [9-12]. 


\subsection{IGBTs Converter}

The structure of an IGBT inverter arm s is illustrated by the following figure [9-12]:

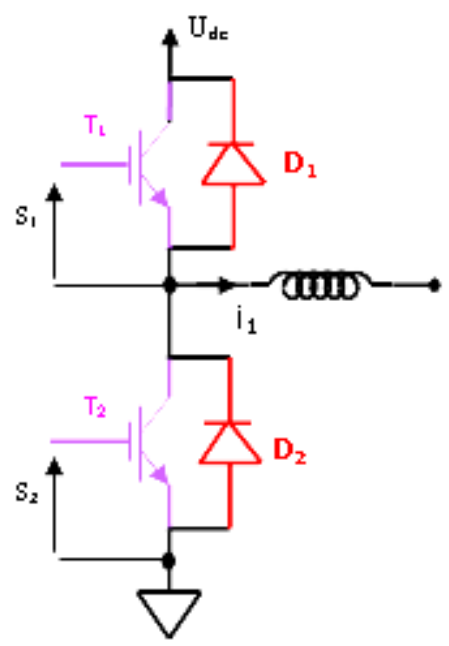

Figure 2. Structure of an arm of IGBT inverter.

The relationship of the conduction losses in the transistors is as follows:

$$
P_{\text {con } T}=\frac{6}{2} \times \rho \times V_{c e}\left(I_{m}\right) \times I_{m}
$$

Where $\rho$ is the duty ratio of the control signals of the transistors, $\mathrm{I}_{\mathrm{m}}$ is the average current on a half period and $\mathrm{V}_{\mathrm{ce}}$ is the collector-emitter voltage.

The switching losses in the transistors are also derived by the following equation:

$$
P_{\text {com } T}=\frac{6}{2} \times f_{s w} \times \frac{U_{d c}}{E_{w}} \times\left(E_{o n}\left(I_{m}\right)+E_{\text {off }}\left(I_{m}\right)\right)
$$

Where $f_{s w}$ is the switching frequency, $U_{d c}$ is the DC bus voltage, $\mathrm{E}_{\text {off }}$ is the energy dissipated in the opening, $\mathrm{E}_{\text {on }}$ is the energy dissipated during closing and $\mathrm{E}_{\mathrm{w}}$ is the DC voltage after manufacturers testing when determining the energy dissipated at the opening and closing.

Conduction losses in the diodes are also estimated by the following relationship:

$$
P_{\text {cond }}=\frac{6}{2} \times(1-\rho) \times V_{d}\left(I_{m}\right) \times I_{m}
$$

The following table provides an overview of results of tests of failures IGBT converters and their genesis [9]. Analysis of these failures, their genesis, their propagation leading to the default setting of the component to characterize its final state, plays an essential role in the development strategies of

\begin{tabular}{|c|c|c|c|c|c|c|c|}
\hline Module & Cycling Type & $\Delta \mathrm{Tj}\left({ }^{\circ} \mathrm{C}\right)$ & $\operatorname{Tjmax}\left({ }^{\circ} \mathrm{C}\right)$ & $\Delta$ Tsemelle $\left({ }^{\circ} \mathrm{C}\right)$ & Tplancher $\left({ }^{\circ} \mathrm{C}\right)$ & Nf (kcycles) & stop test \\
\hline A6 & Long $(18 s-43 s)$ & 95 & 145 & 60 & 50 & 61 & Vcesat $(+10 \%)$ \\
\hline A7 & Long $(18 s-43 s)$ & 95 & 145 & 60 & 50 & 37 & IGBT fault \\
\hline A9 & Long $(18 s-43 s)$ & 95 & 145 & 60 & 50 & 37 & IGBT fault \\
\hline GEM 002 & Long $(18 s-43 s)$ & 95 & 145 & 60 & 50 & 39 & IGBT fault \\
\hline $\mathrm{C} 1$ & Long $(15 s-45 s)$ & 60 & 150 & 30 & 90 & 207 & diode fault \\
\hline $\mathrm{C} 2$ & Long $(15 s-45 s)$ & 60 & 150 & 30 & 90 & 520 & Vcesat $(+2,3 \%)$ \\
\hline GEM 003 & Long $(10 s-30 s)$ & 80 & 170 & 40 & 90 & 44 & IGBT fault \\
\hline GEM 005 & Long $(10 s-30 s)$ & 80 & 170 & 40 & 90 & 56 & IGBT fault \\
\hline GEM 006 & Long $(10 s-30 s)$ & 80 & 170 & 40 & 90 & 60 & IGBT fault \\
\hline GEM 007 & Long $(10 s-30 s)$ & 80 & 170 & 40 & 90 & 107 & diode fault \\
\hline GEM 009 & Long $(10 s-30 s)$ & 80 & 170 & 40 & 90 & 72 & IGBT fault \\
\hline GEM 0010 & Long $(10 s-30 s)$ & 100 & 160 & 40 & 60 & 48 & IGBT fault \\
\hline GEM 0011 & Long $(10 s-30 s)$ & 100 & 160 & 40 & 60 & 38 & IGBTfault \\
\hline
\end{tabular}
redundancy and reconfiguration converters IGBT.

Table 1. Review of failuresIGBTs.

The global model of the losses in the power chain is implanted under the environment of Matlab/Simulink according to the figure $3[9]$ : 


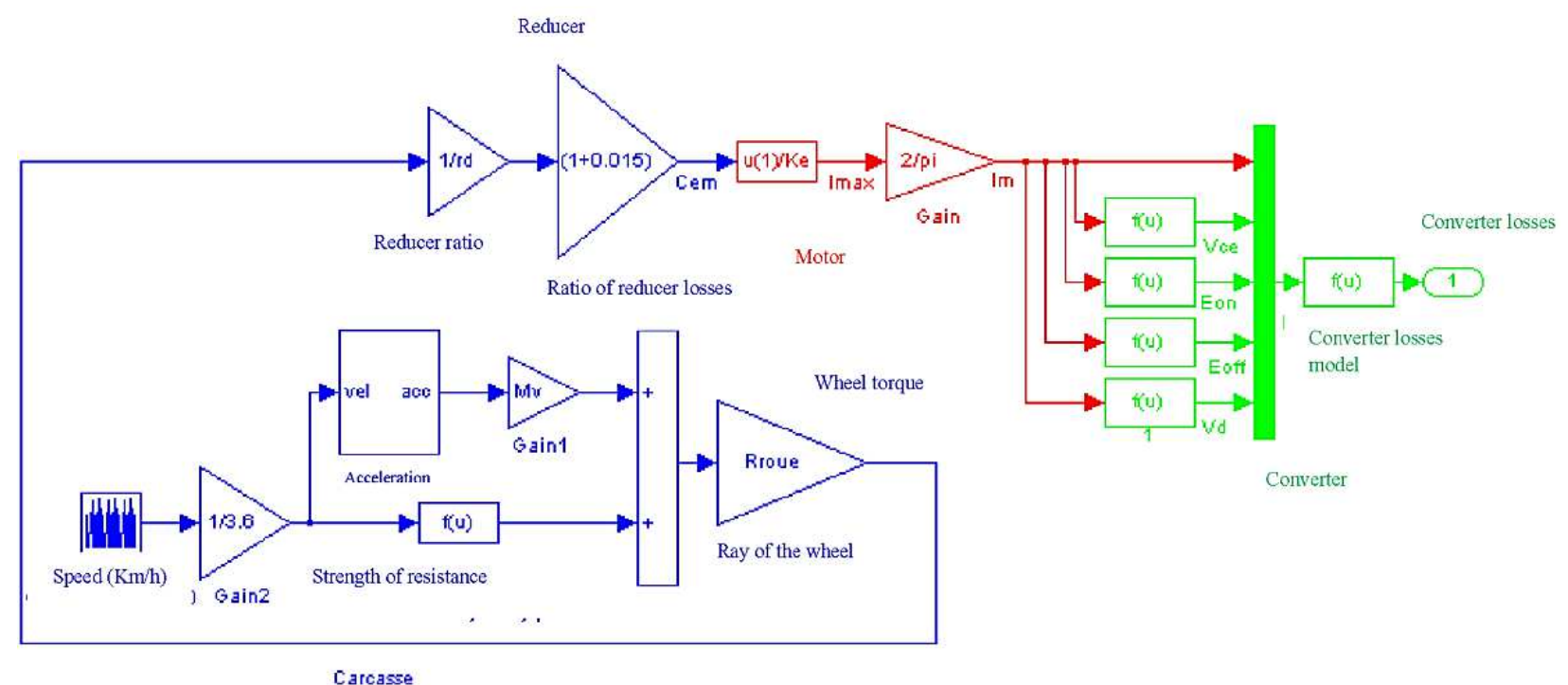

Figure 3. Middle model of the losses in the converter with IGBTs.

\subsection{IEs Converter}

The converter with electromagnetic switch has the advantage of a good quality of the armature voltage delivered by this type of the inverter and to the absence of power dissipation by conduction and switching.

The structure of a converter arms to electromagnetic switches equipped with the average power control circuit is illustrated by the following figure [9]:

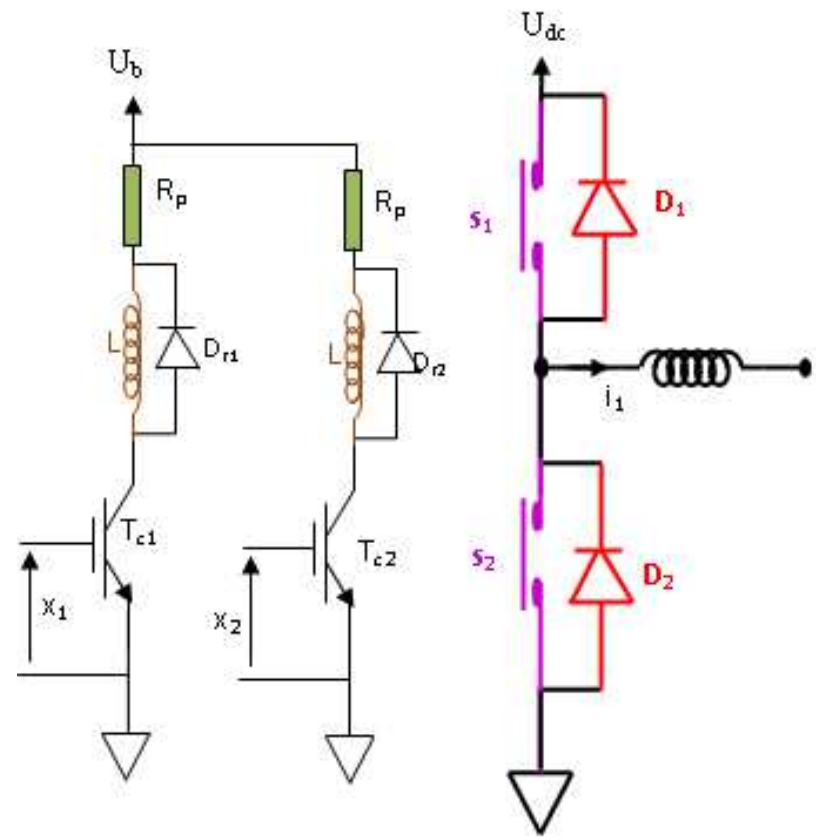

Figure 4. Structure of an arm of the power converter of the control circuit provided

The operating sequences of the power converter to IEs are illustrated by the following figure:

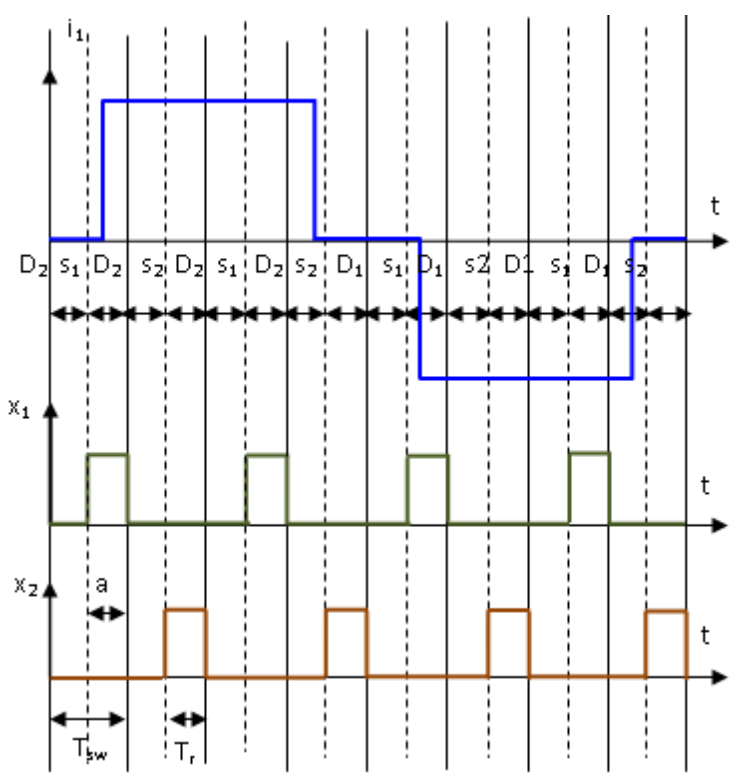

Figure 5. Operating sequences of the power converter in IEs.

The copper losses dissipated by the control coils are given by the following relationship:

$$
P_{j b}=\rho \times n_{m} \times \frac{6}{2} \times\left(R_{p}+R_{b o b}\right) \times I^{2}
$$

Wherein $\mathrm{n}_{\mathrm{m}}$ is the number of coils unit for controlling an inverter arm, $R_{p}$ is the protection resistance of the coil control, $R_{\text {bob }}$ is the resistance of the control coil, $I$ is the excitation current of the control coil and $\rho$ is the duty cycle of the control signals to the converter IEs given by [2-8]:

$$
\rho=\frac{a}{T_{s w}}
$$

The power transferred to the movement of the rod is 
estimated by the following relationship:

$$
\mathrm{P}_{\mathrm{tb}}=\rho \times \mathrm{n}_{\mathrm{m}} \times \frac{6}{2} \times \frac{\mu_{0} \times \mu_{\mathrm{r}}}{4} \times \frac{\mathrm{I}^{2} \times \mathrm{N}_{\mathrm{sb}}^{2}}{\left(\mathrm{E}_{\mathrm{cu}}+\mathrm{D}_{\mathrm{co}}-\mathrm{x}_{\mathrm{t}}\right)^{2}} \times \mathrm{V}_{\mathrm{t}}
$$

Where $V_{t}$ is the speed of the rod.

Hence the losses in the control coils $\left(\mathrm{P}_{\mathrm{ea}}\right)$ are expressed by the following equation:

$$
\mathrm{P}_{\mathrm{ea}}=\mathrm{P}_{\mathrm{jb}}+\mathrm{P}_{\mathrm{tb}}
$$

Conduction losses in the diodes are estimated by the following relationship [2,-9]:

$$
\mathrm{P}_{\mathrm{conD}}=\frac{6}{2} \times \frac{\mathrm{T}_{\mathrm{r}}}{\mathrm{T}_{\mathrm{sw}}} \times \mathrm{V}_{\mathrm{d}}\left(\mathrm{I}_{\mathrm{m}}\right) \times \mathrm{I}_{\mathrm{m}}
$$

Where $\mathrm{T}_{\mathrm{r}}$ is the time delay in the closing and opening of the shaft.

The model of the total losses in the static converter IEs is implanted under the environment of Matlab / Simulink according to the following block diagram:

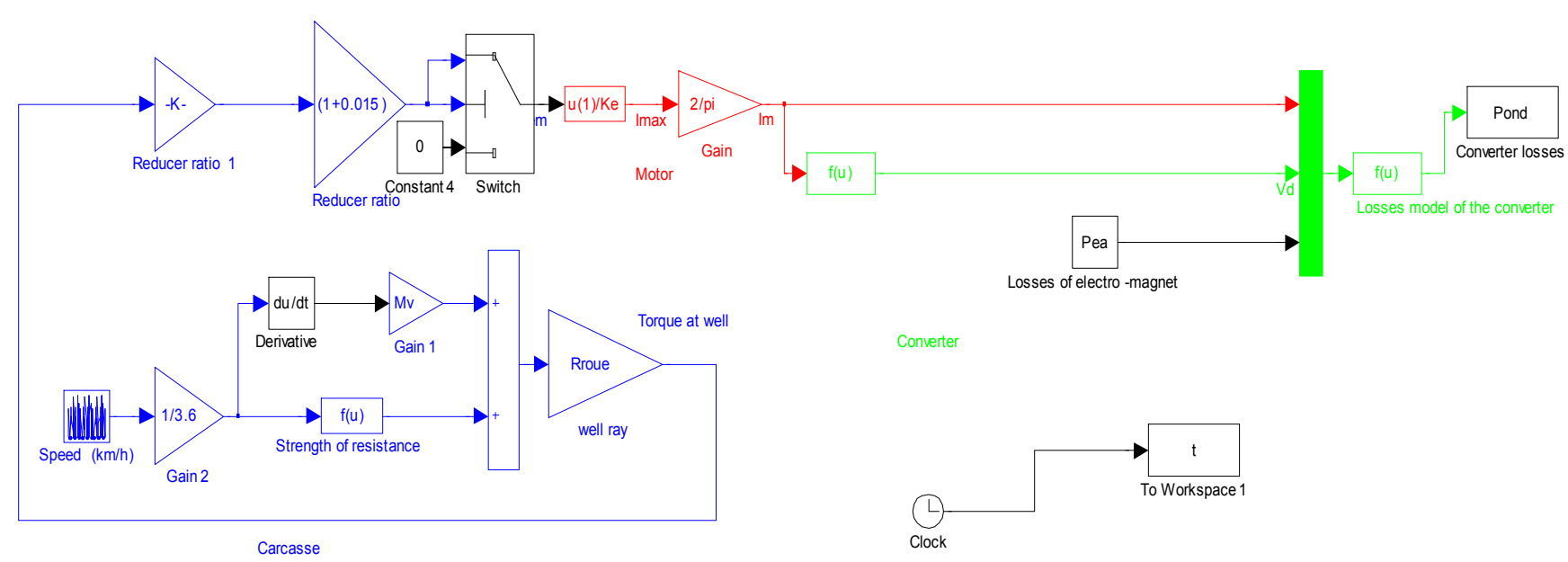

Figure 6. Average model of the losses in the electromagnetic converter.

\subsection{Model of the Power Converter}

The model of the power converter based on the comparison of the reference voltages (the voltage of the motor so that it can develop the necessary torque to the movement of EV), regulator outputs of the phase currents, to a triangular signal with $\mathrm{f}_{\mathrm{sw}}$ frequency less than the frequency of opening and closing of the electromagnetic switches relies [1-12].

$$
f_{s w}=\frac{f_{i e}}{n_{q}}
$$

Where $n_{q}$ is the quality factor of supply voltages and $f_{i e}$ is the frequency of delay to the opening and closing of the electromagnetic switches:

$$
\begin{gathered}
f_{i e}=\frac{1}{T_{r}} \\
T_{r}=T_{\text {off }}=T_{o n}=0.0036 \mathrm{~s}
\end{gathered}
$$

The output signals of three comparators pulsate to the rhythm of the reference voltages. These signals are attacking three hysteresis of between $+\mathrm{U}_{\mathrm{dc}}$ and $-\mathrm{U}_{\mathrm{dc}}$ to reproduce the shape of the supply voltages supplied by the power converter.

The delay in the opening and closing is modeled by a first order transfer function with unity gain and time constant equal to $\mathrm{T}_{\mathrm{r}}$.

The converter model to electromagnetic switches is implanted under the Matlab / Simulink environment and illustrated by the following figure [9]: 


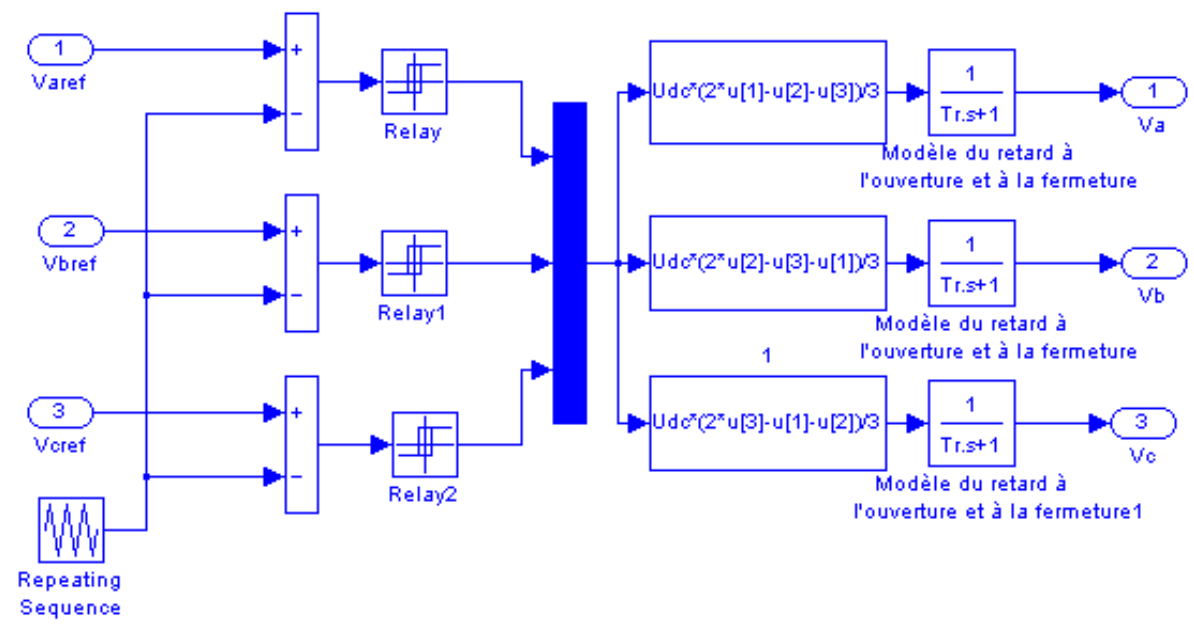

Figure 7. Model converter standardized electromagnetic switches.

\section{Simulation Results}

Figure 8 shows the evolution of total losses for the power train, the first with IGBT and the other with electromagnetic switch (IEs).

Figure 8 show that the total losses of the IGBT structure are much higher than those of the IEs structure. From these results we deduce that the average efficiency of the IGBT structure is much lower than that of the structure in IEs.

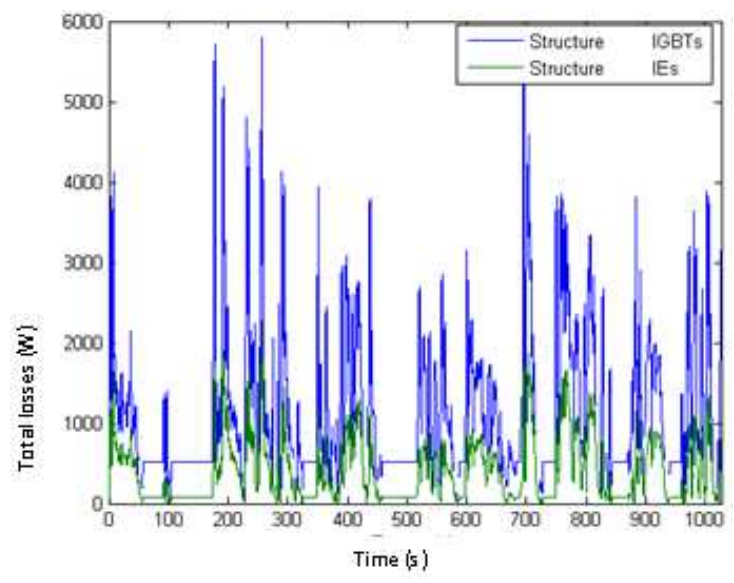

Figure 8. Total losses of the power chain for both structures.

The average yield of the IGBT structure, without considering the losses in the inverter is about $\mathrm{RI}_{\mathrm{GBT}}=0.92$ and $\mathrm{R}_{\mathrm{IGBT}}^{\prime}=0.82$ while considering the losses in the inverter.

The yield structure of the IEs $\left(\mathrm{R}_{\text {Ies }}=0.94\right)$ is significantly higher than that of the IGBT structure. So we can conclude that the structure IEs is more economical than the one IGBTs.

\section{Conclusion}

In this article, we presented a comparative and selective study of twopower chain structures, one with IGBTs and the other with IEs. Indeed, a loss model in the power chainin both cases structuresshowed that the structure with IEs dissipates much less power than in IGBT and this is due mainly to the size of the losses in the converter to IGBTs.

Finally, the power chainwith IEs is chosen to solve the problem the electric traction having less dissipative and cheaper compared to the one IGBT. This power train equipped with the recovery system also modeled on Matlab / Simulink environment therefore present an attractive solution to the problem of electric vehicles drive.

\section{References}

[1] S.TOUNSI: «Conception et OptimisationSystématiques de la Chaîne de Puissance des VéhiculesElectriques»; Habilitation universitaire, EcoleNationaled'Ingénieurs de Sfax - Tunisie, Mai 2012.

[2] M. HADJ KACEM , « Conception des ComposantsElectriques de la Chaîne de Puissance d'un VéhiculeElectrique»; Thèse de Doctorat 2013. ENIS Tunisie.

[3] M. HADJ KACEM, S.TOUNSI et R. NEJI: «Optimization of Cutting Frequency Electromagnetic Interrupter»; International Journal of Computer Applications, Volume 67, $\mathrm{N}^{\circ} 21$, Avril 2013.pp.23-27.

[4] R. NEJI, S. TOUNSI et F. SELLAMI: «Contribution to the definition of a permanent magnet motor with reduced production cost for the electrical vehicle ropulsion»; European Transactions on Electrical Power (ETEP), 2006, 16: pp. 437-460.

[5] M.HADJ KACEM, S.TOUNSI et R. NEJI: « Systemic Design and Control of Electric Vehicles Power Chain »; IJSTR, volume1, $\mathrm{n}^{\circ}$ 2012,pp.73-81.

[6] A. AMMOUS, B. ALLARD, H. MOREL: «Transient temperature mesurements and modeling of IGBT's under short circuit», IEEE transaction electronic devices, vol. $13, \mathrm{n}^{\circ} 1$, 1998, p. 12-25.

[7] V. SMET: «Fiabilité et analyse de défaillances de modules de puissance à IGBT»; JCGE'08 LYON, 16 et 17 décembre 2008.

[8] M.HADJ KACEM, S.TOUNSI et R. NEJI: « Control of an Actuator DC Energy-saving dedicated to the Electric Traction »; International Journal of Computer Applications (0975 - 8887) Volume 54- No.10, September 2012.pp.20-25. 
[9] S. TOUNSI, M. HADJ KACEM et R. NEJI: « Design of Static Converter for Electric Traction »; International Review on Modelling and Similations (IREMOS) Volume 3, N. 6, December 2010, pp. 1189-119.

[10] Chaithongsuk, S., Nahid-Mobarakeh, B., Caron, J., Takorabet, N., \&Meibody-Tabar, F. : Optimal design of permanent magnetmotors to improvefield-weakening performances in variable speed drives. IndustrialElectronics, IEEE Transactions on, vol 59 no 6, p. 2484-2494, 2012.
[11] Rahman, M. A., Osheiba, A. M., Kurihara, K., Jabbar, M. A., Ping, H. W., Wang, K., \&Zubayer, H. M. : Advances on single-phase line-starthighefficiencyinterior permanent magnetmotors. IndustrialElectronics, IEEE Transactions on, vol 59 no 3, p. 1333-1345, 2012.

[12] C.C Hwang, J.J. Chang : Design and analysis of a high power density and highefficiency permanent magnet DC motor, Journal of Magnetism and Magnetic Materials, Volume 209, Number 1, February 2000, pp. 234-236(3)-Publisher: Elsevier. 